selenium was then coated with shell-lac varnish, and about two hours afterwards again tested in the same manner as before, when the light was found to produce a deflection of 220 divisions, or more than twice the previous amount. The action of radiant heat was similar to that of light in the case of this particular specimen, but I have little doubt that any specimen may be endered more sensitive to light by coating it with varnish or lampblack. I hope that this suggestion will prove of service to those philusophers who may aspire to "hear a beam of light" or to "see by electricity," and shall be glad to hear that such has been the case.

King's College, Strand, March 7

\section{Cave Animals and Multiple Centres of Species}

THE readers of Semper's “Existenzbedingungen der Thiere," now translated into English, will find (vol. ii. p. 268 of the German edition) an interesting discussion on the question of monophyletic or polyphyletic evolution of species, the author decidedly inclinin $y$ to the latter hypothesis. Considering that at the rost of the manifold and difficult problems here involved, there is the relatively simple one of single or multiple centres of each speciss in a biozraphical sense, I take leave to ask the following question, hoping for an answer fron anong your readers versed in these matters.

To me it seems imposible to maintain the single centres of species in a strict and definite sense without also maintaining the single progenitor of each. species, which latter view, formerly considered as a necessary assumption, has been given up by $\mathrm{Mr}$. Darwin in Chapter IV. of the later editions of the "Origin of Species" (5th ed. p. 103, 104). Of course the acceptance of single centres, in the sense of more or less restricted areas of origination, may remain valid for the vast $\mathrm{m}$ ijority of speciesbut this is very different frum considering it, once for all, as "a necessary consequence of the adoption of Darwinian views," as has been formerly said by Mr. Bentham (Nature, vol. ii. p. I12).

Now, I have someti nes thought that there might be a test for the possibility of multiple centres, which, eventually, would amount almost to an experimental demonstration-namely : zehether there are cases of the same species of blind animals occurring in different caves distant from and without subterranean communication with each othere? Should such cases occur it would be most improbable that the animals in question had been transported from one cave to the other in the molified state, and most probable that they had been independently evolved in each cave from identical specie; which entered it from without. I formerly noted one instance perhaps in point, viz. a statement of Prof. Cope's (NATURE, vol. vii. p. II) that " the blind fish of the Wyandotte Cave is the same as that of the Mammoth, the Amblyopsis spelaeus, Dekay," but I am not aware whether subterranean communication is, or has been, impossible in this instance. Perhaps more decisive cases have become known of late?

Freilurg im Breisgau, March 4

D. WetterhaN

\section{Prehistoric Europe}

Will you kindly allow me to correct a clerical error in my letter which appeared in NATURE, vol. xxiii. p. 433. For " 'hash-up' of the species," read " "hash-up' of species." A nu nber of the species from the Upper or Interglacial Bone-be of Mont Perrier (and some of which are mentioned in my letter) are of course too characteristically Pleistocene to be claimed by Prof. Dawkins as Pliocene forms, and do not therefore appeir in his list of Upper Pliocene species to which I referred.

Perth, March 14

JAMES Geikie

\section{Measuring the Height of Clouds}

In Nature, vol. xxiii. p. 244, Mr. Edwin Clark gives a method whereby the height or distance of clouds may be measured. This end has already been attained by me, several years ago, and I believe with adequate success. I have also worked out the method $i_{i}$ detail, so that its practical realisation no longer offers any difficulty. It is very simple and easy, and the apparatus ("nephoscope") is not difficult to make. A full description of the nephoscope will be found in the Zeitschrift der. Oesterreich. Ges. fiur Meteorologie, edited by Jelinek and Hann, vol. ii. p. 337 , in so far as the instrument serves for measuring the direction and velocity of the passage of clouds. In order also to ascertain the absolute height of clouds (N.B. all without calcula- tion) I have introduced an improvement. This and a guide to practical use I have published in the same Zeitschrift (vol, ix. September, 1874, pp. 257-61 ). I believe Mr. Edwin Clark will find in the article referred to his idea fully worked out. C. BRAUN,

Kalocsa, Hungary, March 3 Director of the Observatory

\section{Occultation of 73 Piscium}

I observen here this evening the occultation of 73 Piscium by Jupiter, which was predicted in your "Astronomical Column" under the date December 23, I880 (NATURE, vol. xxiii. p. 183). At Ih. 52m. 3os. G.M.T, the star was hanging on the limb of the planet, and by $\mathrm{rh} .54 \mathrm{~m}$. it had entirely disappeared.

The phenomenon strongly resembled the occultation of a satellite, except that the disappearance was more rapid. But it was not instantaneous a; I had expected. The planet and star appeared to cohere for about one and a half minute. The contrast in their colours was very marked, Jupiter appearing of a yellowish tinge, while the star shone out white like a diamond. During the occultation the red spot was on the planet's disk, and its following end was in about the same meridian as the point of the star's occultation.

I had no micrometer, but I inclose a diagram showing the estimated points of occultation and reappearance.

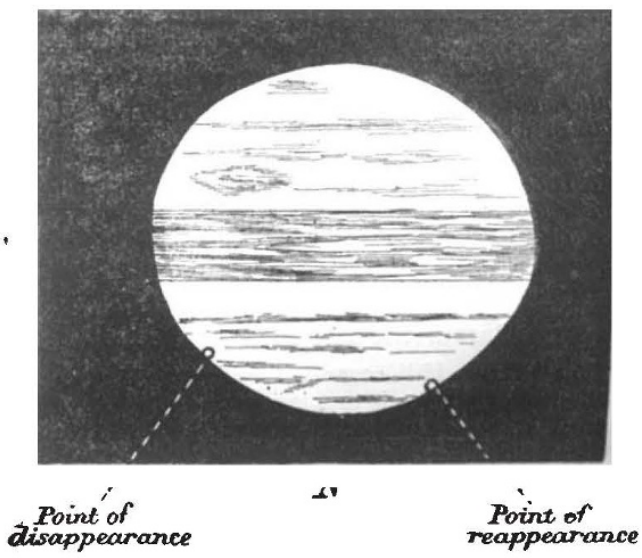

The G.M.T. of reappearance was $2 \mathrm{~b} .44 \mathrm{~m}$., when the star was again observed to hang on to the planet's limb.

The telescope used was a $4 \frac{1}{4}$ inch refractor by Cooke equatorially mounted, with a power of 96 .

The planet was well placed for observation, being nearly in the zenith.

Before and after the occultation Jupiter appeared as if with five moons, the star being almost indistinguishable from the satellites.

As the occultation could not be observed in Europe these few notes may possibly prove of some interest.

A diagonal (prism) eyepiece was used in making the sketch.

Meean Meer, Lahore, February $3 \quad$ H. Collet

\section{Colours of British Butterflies}

MosT of the protectively coloured British butterflies pair either on the ground as the "Blues," or on low herbage as the majority, or on the leaves of trees, as:some of the "Hair-streaks," and with closed wings. The wings of both sexes are usually opened as widely as possible immediately before copulation.

I have been struck by the fact, which I may mention in reference to the remark of Mr. J. Innes Rogers (NATURE, vol. xxiii. p. 435$)$, that $I$ have never seen the "peacock" attacked by any British bird, and I have often watched him flaunting hi; colours in the presence of shrike; flycatchers, and other-one would imagine dangerous - conpany.

Ashby Parva, Lutterworth, March II

Lecture Representation of the Aurora Borealis

I HAVE recently employ'ed a simple device for giving to an audiense a vivid ilea of an aurora, and that has been to paint a 